\title{
Association between exposure to particulate matter and admissions for respiratory diseases in adults aged 50 years and over
}

\author{
João K. P. Moraes*, Ana C. G. César.
}

\begin{abstract}
Air pollution is responsible for causing damage to the respiratory tract, leading to hospitalizations and deaths due to exposure. The objective was estimate the association between exposure to particulate matter (PM10) and hospital admissions for respiratory disease in adults aged over 50 years, living in Taubaté (SP). It was an ecological time series study, conducted from January 1, 2016 to December 31, 2016, using the daily hospitalizations for respiratory diseases (ICD-10: J00-J99) available in DATASUS site, the daily levels of pollutants (PM10, CO, NO2, O3), and temperature and relative air, available in CETESB site. The average daily admissions was $1.3(\mathrm{SD}=1.35$; $\min 0$, $\max 8$.). The multipollutant model, the hospital admissions were associated with exposure to PM10 at lag 3 (RR=1.02, 95\%Cl: 1.01 1.03), lag $4(R R=1.03,95 \% \mathrm{Cl}: 1.01-1.04)$, lag $5(R R=1.02,95 \% \mathrm{Cl}: 1.01-1.04)$, lag $6(R R=1.02,95 \% \mathrm{Cl}: 1.01-1.03)$ and lag 7 (RR=1.02; 95\% $\mathrm{Cl}: 1.01-1.03)$. The increase of $5 \mu \mathrm{g} / \mathrm{m}^{3} \mathrm{PM} 10$ concentation increased in 8.5 to 11.7 percentage points the risk of hospitalizations.
\end{abstract}

\section{Key words:}

Particulate matter, Respiratory diseases, Series ecological study.

\section{Introduction}

Respiratory diseases have stricken the Brazilian population strongly, in 2015, approximately 1,200,000 hospitalizations were registered by the Brazilian National Health System (SUS), causing about 150 thousand deaths, costing approximately US $\$ 1$ billion and 200 million to the country ${ }^{1}$.

Air pollutants found mainly in large urban centers, lead to respiratory diseases, even at concentrations below the air quality standard. The highest incidence of asthma, bronchitis, sinusitis, rhinitis, pneumonia, pulmonary emphysema, among others, is associated with variations in concentrations of various atmospheric pollutants ${ }^{2}$.

The municipality of Taubaté, SP, is the second largest industrial and commercial center in mesoregion of the Paraíba valley. Its vehicular fleet in 2016 reached 203,000 vehicles, occupying the 19th place in the state of São Paulo ${ }^{3}$.

Thus, the objective of this study was to estimate the association between particulate matter with an aerodynamic diameter of 10 microns or less (PM10) and hospitalizations for respiratory diseases in adults aged 50 years and over, living in Taubaté, SP, Brazil.

\section{Results and Discussion}

This investigation consists of an ecological timeseries study of hospital admissions to respiratory diseases (ICD-10, J00-J99) of adults aged 50 years and over, residents of Taubaté, obtained from the SUS website (DATASUS). Daily ozone $\left(\mathrm{O}_{3}\right)$, nitrogen dioxide $\left(\mathrm{NO}_{2}\right)$, carbon monoxide (CO), particulate material $\left(\mathrm{PM}_{10}\right)$ concentrations and temperature and relative air humidity using data extracted from the site of the Environmental Company of São Paulo (CETESB), in the period January 1, 2016 to December 31, 2016. In 366 days analyzed, 475 hospital admissions occurred during the period with a daily mean of $1.3(S D=1.35)$ and ranging from 0 to 8 hospitalizations per day.

In order to estimate the Relative Risk (RR) of hospital admissions due to respiratory diseases with $\mathrm{PM}_{10}$ concentration and adjusted for the other pollutants, was used Poisson regression (Statistica v.8 software), with delays of 0 to 7 days, with $p$ value $<0.05$.

The multipollutant model, it was seen that admission was significantly associated with exposure to $\mathrm{PM}_{10}$ at lag $3(\mathrm{RR}=1.02,95 \% \mathrm{Cl}: 1.01-1.03)$, lag 4 $(\mathrm{RR}=1.03,95 \% \mathrm{Cl}: 1.01-1.04)$, lag $5(\mathrm{RR}=1.02,95 \% \mathrm{Cl}$ : 1.01-1.04), lag $6(\mathrm{RR}=1.02,95 \% \mathrm{Cl}: 1.01-1.03)$ and $\operatorname{lag} 7$ $(\mathrm{RR}=1.02 ; 95 \% \mathrm{Cl}: 1.01-1.03)$. An increase of $5 \mu \mathrm{g} / \mathrm{m}^{3}$ in $\mathrm{PM}_{10}$ increased the risk of hospital admissions due to respiratory diseases between $8.5 \%$ and $11.7 \%$.

Short-term exposure to $\mathrm{MP}_{10}$ may act as a risk factor, increasing morbidity and mortality from respiratory diseases. It is estimated that all-cause mortality, not only respiratory mortality, increases by $0.2-0.6 \%$ in response to an increase of $10 \mu \mathrm{g} / \mathrm{m}^{3}$ of $\mathrm{MP}_{10}$ concentration ${ }^{4}$.

\section{Conclusions}

This study suggests the association between exposure to $\mathrm{PM}_{10}$ and hospital admissions for respiratory diseases of adults aged 50 years or more, after 3 to 7 days of exposure. A $5 \mu \mathrm{g} / \mathrm{m}^{3}$ increase of $\mathrm{PM}_{10}$ was associated with a $8.5 \%-11.7 \%$ increase in risk of hospital admissions.

\section{Acknowledgement}

The author João K. P. Moraes thanks the Federal Institute of São Paulo for the scholarship of scientific initiation.

\footnotetext{
${ }^{1}$ BRAZIL. Ministry of Health - Datasus [Internet]. Department of Informatics of the Unified Health System. Available from <http://tabnet.datasus.gov.br/cgi/tabcgi.exe?sih/cnv/nrmt.def $>$. Access on 23 Jun. 2019

${ }^{2}$ FREITAS, C.U.; LEON, A. P.; JUNGER, W.; GOUVEIA, N. Air pollution and its impacts on health in Vitoria, Espírito Santo, Brazil. Revista de Saúde Pública v. $50, \mathrm{n} .4, \mathrm{p} .1-9,2016$

${ }^{3}$ National Department of Traffic (DENATRAN) [Internet]. Fleet by municipality and type. 2016. Available from http://www.denatran.gov.br/estatistica/261-frota2016. Access on 13 Oct 2018.

${ }^{4}$ SAMOLI. E.; PENG, R.; RAMSAY, T. et al. Acute effects of ambient particulate matter on mortality in Europe and North America: results from the APHENA Study. Environmental Health Perspectives, v. 116, n. 11, p.1480-6, 2008.
} 